\title{
Effect of Respiratory Impairment on the Outcomes of Primary Percutaneous Coronary Intervention in Patients With ST-Segment Elevation Myocardial Infarction and Coronavirus Disease-2019 (COVID-19)
}

\author{
Dario Pellegrini, MD; Luigi Fiocca, MD; Irene Pescetelli, MD; Paolo Canova, MD; \\ Angelina Vassileva, MD; Lara Faggi, PhD; Michele Senni, MD; Giulio Guagliumi, MD
}

\begin{abstract}
Background: Coronavirus Disease-2019 (COVID-19) may impair outcomes of patients with ST-segment elevation myocardial infarction (STEMI). The extent of this phenomenon and its mechanisms are unclear.

Methods and Results: This study prospectively included 50 consecutive STEMI patients admitted to our center for primary percutaneous coronary intervention (PCl) at the peak of the Italian COVID-19 outbreak. At admission, a COVID-19 test was positive in 24 patients (48\%), negative in $26(52 \%)$. The primary endpoint was in-hospital all-cause mortality. Upon admission, COVID-19 subjects had lower PO2/FiO2 (169 [100-425] vs. 390 [302-477], $\mathrm{P}<0.01$ ), more need for oxygen support (62.5\% vs. 26.9\%, $\mathrm{P}=0.02)$ and a higher rate of myocardial dysfunction (ejection fraction $<30 \%$ in $45.8 \%$ vs. $19.2 \%, P=0.04$ ). All patients underwent emergency angiography. In $12.5 \%$ of COVID-19 patients, no culprit lesions were detected, thus $\mathrm{PCl}$ was performed in $87.5 \%$ and $100 \%$ of COVID-19 positive and negative patients, respectively $(P=0.10)$. Despite a higher rate of obstinate thrombosis in the COVID-19 group (47.6\% vs. $11.5 \%, \mathrm{P}<0.01$ ), the $\mathrm{PCl}$ result was similar (TIMI $2-3$ in $90.5 \%$ vs. $100 \%, \mathrm{P}=0.19$ ). In-hospital mortality was $41.7 \%$ and $3.8 \%$ in COVID-19 positive and negative patients, respectively $(\mathrm{P}<0.01)$. Respiratory failure was the leading cause of death $(80 \%)$ in the COVID-19 group, frequently associated with severe myocardial dysfunction.
\end{abstract}

Conclusions: In-hospital mortality of COVID-19 patients with STEMI remains high despite successful PCI, mainly due to coexisting severe respiratory failure. This may be a critical factor in patient management and treatment selection.

Key Words: Acute coronary syndromes; Acute myocardial infarction; Coronary revascularization; Percutaneous coronary intervention; SARS-COV2

$\mathbf{S}$ ince its appearance, COVID-19 (Coronavirus Disease-2019) has claimed a heavy human toll. Severe, acute respiratory failure caused by interstitial pneumonia is the leading cause of mortality and morbidity, but the disease seems to target multiple organs. In particular, there are signals of a significant impact on the cardiovascular system, and reports have suggested that patients with ST-segment elevation myocardial infarction (STEMI) may have an impaired outcome. ${ }^{1}$

Multiple mechanisms have been proposed, ranging from a direct involvement of the myocardium, ${ }^{2}$ to a higher risk of ischemic events triggered by acute respiratory failure. ${ }^{3}$ Moreover, the fast diffusion and severity of the epidemic has posed relevant challenges to emergency medical systems, which may be overwhelmed by the impressive number of simultaneous cases of respiratory failure and unable to

\section{Editorial p1708}

offer a prompt reaction to other time-dependent conditions like STEMI. ${ }^{4}$ Finally, risk of exposure of personnel during percutaneous coronary intervention (PCI) may be a critical issue. Thus, international societies and health authorities have issued statements on the management of acute coronary syndromes and the organization of STEMI networks in the COVID-19 era., ${ }^{\mathbf{6}}$ Thrombolysis was proposed as a possible alternative to primary PCI, due to possible advantages related to shorter time to reperfusion, lower resource demand, and reduced risks of exposure for healthcare workers. $^{7}$

In Italy, COVID-19 first appeared in the last week of February 2020 and spread fast across the northern part of

\footnotetext{
Received November 11, 2020; revised manuscript received December 11, 2020; accepted December 28, 2020; J-STAGE Advance Publication released online March 2, 2021 Time for primary review: 17 days

Cardiovascular Department, Papa Giovanni XXIII Hospital, Bergamo, Italy

The first two authors contributed equally to this manuscript (D.P., L.F.).

Mailing address: Dario Pellegrini, MD, Cardiovascular Department, Papa Giovanni XXIII Hospital, Piazza OMS, 124127 Bergamo, Italy. E-mail: dar.pellegrini@gmail.com

All rights are reserved to the Japanese Circulation Society. For permissions, please e-mail: cj@j-circ.or.jp

ISSN-1346-9843
} 


\begin{tabular}{|c|c|c|c|c|}
\hline & $\underset{(n=50)}{\text { All }}$ & $\begin{array}{l}\text { COVID } \\
(n=24)\end{array}$ & $\begin{array}{c}\text { Non-COVID } \\
(n=26)\end{array}$ & $P$ value \\
\hline Age (years) & $67.04 \pm 12.45$ & $69.63 \pm 11.00$ & $64.65 \pm 13.04$ & 0.08 \\
\hline Age $>75$ years, $n(\%)$ & $14(28.0)$ & $9(37.5)$ & $5(19.2)$ & 0.21 \\
\hline Male gender, n (\%) & $42(84.0)$ & $20(83.3)$ & $22(84.6)$ & 1.000 \\
\hline BMI & $26.33 \pm 3.37$ & $26.60 \pm 3.36$ & $26.11 \pm 3.43$ & 0.62 \\
\hline $\mathrm{BMI}>30, \mathrm{n}(\%)$ & $7(14.0)$ & $4(16.7)$ & $3(11.5)$ & 0.70 \\
\hline History of smoking, $\mathrm{n}(\%)$ & $17(34.0)$ & $7(29.2)$ & $10(38.5)$ & 0.77 \\
\hline Hypertension, n (\%) & $31(62.0)$ & $17(70.8)$ & $14(53.9)$ & 0.25 \\
\hline Dyslipidemia, n (\%) & $32(64.0)$ & $15(62.5)$ & $17(65.4)$ & 1.00 \\
\hline Diabetes, n (\%) & $14(28.0)$ & $10(41.7)$ & $4(15.4)$ & 0.06 \\
\hline Insulin therapy, n (\%) & $4(8.0)$ & $3(12.5)$ & $1(3.9)$ & 0.34 \\
\hline Stroke, n (\%) & $3(6.0)$ & $2(8.3)$ & $1(3.9)$ & 0.60 \\
\hline Peripheral arterial disease, $\mathrm{n}(\%)$ & $5(10.0)$ & $4(16.7)$ & $1(3.9)$ & 0.18 \\
\hline Myocardial infarction, n (\%) & $12(24.0)$ & $7(29.2)$ & $5(19.2)$ & 0.51 \\
\hline Previous PCl, n (\%) & $14(28.0)$ & $9(37.5)$ & $5(19.2)$ & 0.21 \\
\hline Previous CABG, n (\%) & $5(10.0)$ & $3(12.5)$ & $2(7.7)$ & 0.66 \\
\hline HF with reduced EF $(<40 \%), n(\%)$ & $1(2.1)$ & $0(0)$ & $1(4.0)$ & 1.00 \\
\hline Renal failure, $\mathrm{n}(\%)$ & $7(14.0)$ & $5(20.8)$ & $2(7.7)$ & 0.24 \\
\hline
\end{tabular}

BMI, body mass index; CABG, coronary bypass graft; COVID, Coronavirus Disease-2019; EF, ejection fraction; HF, heart failure; $\mathrm{PCl}$, percutaneous coronary intervention.

the country, with a unique intensity in the area surrounding Bergamo. On 8 March, the Health Authorities of Lombardy Region urged a reorganization of the network for timedependent diseases, including STEMI; few Macro-hubs were identified, ${ }^{\mathbf{8}}$ and ASST Papa Giovanni XXIII, a 1,080bed tertiary hospital, became the hub center for an area that accounted for $1,150,000$ inhabitants.

The aim of the present study was to compare the procedural and in-hospital outcome of COVID-19 vs. control patients undergoing emergency invasive coronary procedures for STEMI at peak intensity of the local outbreak.

\section{Methods}

\section{Study Setting and Population}

From 8 March to 20 April 2020 we performed a prospective, observational study including all consecutive patients admitted to our catheterization laboratory for primary PCI due to STEMI. Upon admission, all patients underwent a nasal swab or endotracheal aspirate to detect Severe Acute Respiratory Syndrome - Coronavirus 2 (SARS-COv2) infection by real-time reverse transcriptase-polymerase chain reaction (RT-PCR) reaction assay. ${ }^{9}$ All patients underwent emergency coronary angiography upon admission, and primary PCI was performed in all cases in which a culprit lesion was detected. As per clinical practice at the hospital, invasive revascularization was the suggested treatment strategy, and fibrinolysis was not advised. Operators were blinded to the results of the COVID-19 tests, as processing times of the samples required 3-6h. Additional interventions and pharmacological therapy were administered according to international guidelines and local standard of practice. COVID-19 therapy followed local protocols, based on the recommendations of the Italian Ministry of Health and the World Health Organization. 10,11

The primary endpoint of the study was in-hospital allcause mortality.

The study complies with the Declaration of Helsinki and was approved by the local Ethical Review Board (ERB) of Papa Giovanni XXIII Hospital, code 82/20. To avoid transmission of the disease and to minimize the risk of contamination through paper documents, oral informed consent was obtained, as per local protocol.

\section{Data Sources and Definitions}

We collected clinical, angiographic, and procedural data from each subject. Baseline characteristics were obtained from the patient or from electronic medical records. STEMI was defined according to the Fourth Universal Definition of myocardial infarction. ${ }^{3}$ Obstructive coronary artery disease (CAD) was defined as the angiographic evidence of a stenosis $>50 \%$ on visual estimation. During in-hospital stay, we recorded all major events (death, stroke, heart failure, recurrence of myocardial infarction, target vessel failure, stent thrombosis, pulmonary embolism). Definitions of study variables are listed in the Supplementary File.

\section{Statistical Analysis}

Continuous variables were reported as the mean value and standard deviation (SD), or median value and interquartile range (IQR), as appropriate. Categorical variables were reported as count and percentage. In the case of continuous variables, an unpaired t-test or a Wilcoxon-Mann-Whitney test were used to assess between-groups differences, respectively, for normal and non-normal distribution. In the case of categorical variables, a chi-squared or Fisher's exact test were used, when appropriate. A 2-sided $\mathrm{P}$ value $<0.05$ was considered statistically significant.

\section{Results}

We enrolled 50 consecutive patients, 24 (48\%) with confirmed concomitant COVID-19 disease. The clinical characteristics of the study population are reported in Table 1. The mean age was $67.04 \pm 12.45$ years, $84 \%$ were male, with a relevant prevalence of established cardiovascular risk 


\begin{tabular}{|c|c|c|c|c|}
\hline & $\begin{array}{l}\text { Total } \\
(n=50)\end{array}$ & $\begin{array}{l}\text { COVID } \\
(n=24)\end{array}$ & $\begin{array}{l}\text { Non-COVID } \\
(n=26)\end{array}$ & $P$ value \\
\hline Localization of STEMI ( $\mathrm{n}(\%)$ ) & & & & 0.15 \\
\hline Anterior & $29(58.0)$ & $15(62.5)$ & $14(53.9)$ & - \\
\hline Inferior & $14(28.0)$ & 8 (33.3) & $6(23.1)$ & - \\
\hline Lateral & $7(14.0)$ & $1(4.2)$ & $6(23.1)$ & - \\
\hline $\begin{array}{l}\text { Time from onset of cardiac symptoms to Cath } \\
\text { Lab (h) }\end{array}$ & $\begin{array}{c}5.00 \\
{[2.00-7.00]}\end{array}$ & $\begin{array}{c}5.00 \\
{[3.00-7.00]}\end{array}$ & $\begin{array}{c}4.00 \\
{[2.00-8.30]}\end{array}$ & 0.47 \\
\hline Late presentation STEMI (>6h) & $16(37.2)$ & $8(42.1)$ & $8(33.3)$ & 0.75 \\
\hline Systolic BP (mmHg) & $118.02 \pm 26.97$ & $114.83 \pm 23.96$ & $121.08 \pm 29.75$ & 0.42 \\
\hline Systolic BP $\leq 100 \mathrm{mmHg}$ & $16(32.0)$ & $9(37.5)$ & 7 (26.9) & 0.55 \\
\hline Heart rate (beats/min) & $\begin{array}{c}86.00 \\
{[76.75-98.50]}\end{array}$ & $\begin{array}{c}86.00 \\
{[77.50-102.50]}\end{array}$ & $\begin{array}{c}86.50 \\
{[75.75-98.50]}\end{array}$ & 0.87 \\
\hline Killip class $3-4$ at presentation & $8(16.0)$ & $8(33.3)$ & 0 & $<0.01$ \\
\hline LVEF at presentation (\%) & $43.89 \pm 10.50$ & $41.33 \pm 11.98$ & $46.77 \pm 8.31$ & 0.07 \\
\hline LVEF $<40 \%$ at presentation & $16(32.0)$ & $11(45.8)$ & $5(19.2)$ & 0.04 \\
\hline Chest pain at presentation & $43(86.0)$ & $20(83.3)$ & $23(88.5)$ & 0.70 \\
\hline History of dyspnea & $13(28.9)$ & $13(59.1)$ & $0(0)$ & $<0.01$ \\
\hline History of fever & $11(23.4)$ & $11(47.8)$ & $0(0)$ & $<0.01$ \\
\hline
\end{tabular}

Data are presented as $\mathrm{n}(\%)$, mean \pm standard deviation or median [interquartile range] unless otherwise indicated. BP, blood pressure; COVID, Coronavirus Disease-2019; LVEF, left ventricular ejection fraction; STEMI, ST-elevation myocardial infarction.

\begin{tabular}{|c|c|c|c|c|}
\hline & $\begin{array}{c}\text { Total } \\
(n=50)\end{array}$ & $\begin{array}{l}\text { COVID } \\
(n=24)\end{array}$ & $\begin{array}{c}\text { Non-COVID } \\
(n=26)\end{array}$ & $P$ value \\
\hline $\mathrm{PaO} / \mathrm{FiO} 2$ & $\begin{array}{c}357.00 \\
{[146.28-468.34]}\end{array}$ & $\begin{array}{c}169.23 \\
{[100.00-425.00]}\end{array}$ & $\begin{array}{c}390.00 \\
{[302.00-477.0]}\end{array}$ & $<0.01$ \\
\hline $\mathrm{PaO} 2 / \mathrm{FiO} 2<100$ & $6(14.0)$ & $6(26.1)$ & $0(0)$ & 0.02 \\
\hline Interstitial pneumonia & $16(32.0)$ & $13(54.2)$ & $3(11.5)$ & $<0.01$ \\
\hline Ventilation modality & & & & 0.07 \\
\hline Room air & $28(56.0)$ & $9(37.5)$ & $19(73.1)$ & - \\
\hline Low-flow oxygen & $3(6.0)$ & $1(4.2)$ & $2(7.7)$ & - \\
\hline Non-rebreather mask & $13(26.0)$ & $9(37.5)$ & $4(15.4)$ & - \\
\hline CPAP & $2(4.0)$ & $2(8.3)$ & $0(0)$ & - \\
\hline ETI & $4(8.0)$ & $3(12.5)$ & $1(3.9)$ & - \\
\hline Need for ventilatory support (CPAP or ETI) & $6(12.0)$ & $5(20-8)$ & $1(3.8)$ & 0.09 \\
\hline Need for oxygen support & $22(44.0)$ & $15(62.5)$ & 7 (26.9) & 0.02 \\
\hline
\end{tabular}

Data are presented as $n(\%)$, or median [interquartile range] unless otherwise indicated. CPAP, continuous positive airways pressure ventilation; COVID, Coronavirus Disease-2019; ETI, endotracheal intubation; PaO2/FiO2, values refer to those taken at admission.

factors (62\% had hypertension, and $28 \%$ diabetes mellitus). COVID-19 patients shared similar baseline characteristics with non-COVID patients, apart from an older, yet nonrelevant, age $(70 \pm 11$ vs. $65 \pm 13$ years respectively, $\mathrm{P}=0.08)$, and a higher rate of diabetes $(42$ vs. $15 \%, \mathrm{P}=0.06)$.

Prior history of heart failure with reduced ejection fraction (i.e., $<40 \%$ ) was rare $(2.1 \%)$ and equally represented in both groups. Among the study population, 39 patients $(78 \%)$ were directly admitted to our hospital with STEMI, $4(8 \%)$ were transferred from local spoke centers, and 7 (14\%) developed signs and/or symptoms of MI during hospitalization (in 5 subjects, for COVID-19 disease).

Delayed presentation $(>6 \mathrm{~h}$ from cardiac symptoms onset to admission) was noticed in approximately one-third $(37 \%)$ of all cases, possibly due to the saturation of the emergency care system in the pandemic area, with no relevant differences between the groups (Table 2). In the days prior to admission, $48 \%$ of COVID-19 patients reported fever and $59 \%$ dyspnea, compared to $0 \%$ in the non-COVID group $(\mathrm{P}<0.01$ for both comparisons $)$, compared to $0 \%$ in the non-COVID group $(\mathrm{P}<0.01$ for both comparisons). Time from onset of COVID-like symptoms to admission was 10 (6.5-12.5) days. Compared to controls, COVID-19 presented more often with an advanced Killip class (class 3-4 in 33 vs. $\%$ of COVID-19 vs. non-COVID cases respectively, $\mathrm{P}<0.01)$ and a lower ejection fraction (ejection fraction $<40 \%$ in $46 \%$ vs. $17 \%$ respectively, $\mathrm{P}=0.04)$. No relevant differences were detected in laboratory parameters at baseline (Supplementary Table 1).

Upon arrival at the hospital, 13 COVID-19 patients $(54 \%$, Table 3$)$ had chest X-ray findings suggesting interstitial pneumonia. Three patients from the control group $(12 \%, \mathrm{P}<0.01)$ had similar results, although repeated swabs turned out negative. Compared with controls, COVID-19 


\begin{tabular}{|c|c|c|c|c|}
\hline & $\underset{(n=50)}{\text { All }}$ & $\begin{array}{l}\text { COVID } \\
(n=24)\end{array}$ & $\begin{array}{c}\text { Non-COVID } \\
(n=26)\end{array}$ & $P$ value \\
\hline Radial access, $\mathrm{n}(\%)$ & $44(88.0)$ & 20 (83.3) & $24(92.3)$ & 0.41 \\
\hline No angiographic culprit lesion, $\mathrm{n}(\%)$ & $3(4.0)$ & $3(12.5)$ & $0(0)$ & 0.10 \\
\hline Multivessel disease, $\mathrm{n}(\%)$ & $21(35.6)$ & $11(45.8)$ & $10(28.6)$ & 0.27 \\
\hline TIMI flow baseline & & & & 0.76 \\
\hline $0-1, \mathrm{n}(\%)$ & $35(70.0)$ & $16(66.7)$ & $19(73.1)$ & - \\
\hline $2-3, \mathrm{n}(\%)$ & $15(30.0)$ & $8(33.3)$ & $7(26.9)$ & - \\
\hline PCl, n (\%) & $47(94.0)$ & $21(87.5)$ & $26(100.0)$ & 0.10 \\
\hline Target vessel & & & & 0.53 \\
\hline Left main, n (\%) & $1(2.1)$ & $1(4.8)$ & 0 & - \\
\hline LAD, n (\%) & $27(57.5)$ & $13(61.9)$ & $14(53.9)$ & - \\
\hline LCX, n (\%) & $7(14.9)$ & $2(9.5)$ & $5(19.2)$ & - \\
\hline $\mathrm{RCA}, \mathrm{n}(\%)$ & $9(19.2)$ & $3(14.3)$ & $6(23.1)$ & - \\
\hline Graft, n (\%) & $3(6.4)$ & $2(9.5)$ & $1(3.9)$ & - \\
\hline Thrombus aspiration, n (\%) & $20(45.6)$ & $8(38.1)$ & $12(48.0)$ & 0.77 \\
\hline Obstinate thrombosis & $13(27.7)$ & $10(47.6)$ & $3(11.5)$ & $<0.01$ \\
\hline Gp Ilb/llla inhibitors, n (\%) & $12(25.5)$ & 7 (33.3) & $5(19.2)$ & 0.33 \\
\hline Number of stents & $\begin{array}{c}1.00 \\
{[1.00-2.00]}\end{array}$ & $\begin{array}{c}1.00 \\
{[1.00-2.00]}\end{array}$ & $\begin{array}{c}1.50 \\
{[1.00-2.00]}\end{array}$ & 0.44 \\
\hline IABP, n (\%) & $6(12.8)$ & $3(14.3)$ & $3(11.5)$ & 1.00 \\
\hline TIMI flow end-procedure & & & & 0.19 \\
\hline $0-1, \mathrm{n}(\%)$ & $2(4.3)$ & $2(9.5)$ & 0 & - \\
\hline $2-3, \mathrm{n}(\%)$ & $45(95.7)$ & $19(90.5)$ & $26(100)$ & - \\
\hline Procedural time (min) & $\begin{array}{c}70.5 \\
{[53.0-113.5]}\end{array}$ & $\begin{array}{c}81.5 \\
{[46.3-126.0]}\end{array}$ & $\begin{array}{c}65.0 \\
{[53.0-87.5]}\end{array}$ & 0.26 \\
\hline Post-procedural DAPT, n (\%) & $44(93.6)$ & $20(95.2)$ & $26(100)$ & 0.45 \\
\hline Clopidogrel, n (\%) & $12(25.5)$ & $6(28.6)$ & $6(23.1)$ & 0.52 \\
\hline Ticagrelor, n (\%) & $16(36.0)$ & 7 (33.3) & $9(34.6)$ & - \\
\hline Prasugrel, n (\%) & $15(36.2)$ & $6(28.6)$ & $11(42.3)$ & - \\
\hline Cangrelor, n (\%) & $1(2.1)$ & $1(4.8)$ & $0(0)$ & - \\
\hline
\end{tabular}

Data are presented as $\mathrm{n}(\%)$, or median [interquartile range] unless otherwise indicated. COVID, Coronavirus Disease-2019; DAPT, dual antiplatelet therapy; IABP, intra-aortic balloon pump; LAD, left anterior descending; LCX, circumflex artery; $\mathrm{PCl}$, percutaneous coronary intervention; RCA, right coronary artery; TIMI, Thrombolysis in Myocardial Infarction.

subjects presented with significantly lower $\mathrm{PaO} 2 / \mathrm{FiO} 2$ (P/F: 169 [100-425 vs. 390.00 [302.00-477.0] in COVID-19 vs. non-COVID patients, respectively $\mathrm{P}<0.01$ ), and $26.1 \%$ of them (vs. $0 \%$ of controls, $\mathrm{P}=0.02$ ) had a $\mathrm{P} / \mathrm{F}$ under 100 , a recognized threshold for severe acute respiratory distress syndrome (ARDS). ${ }^{12}$

The majority of non-COVID patients (73\%) were breathing room air, few needed a non-rebreather mask $(n=4,15 \%)$ and only 1 had endotracheal intubation due to out-of-hospital cardiac arrest. In contrast, $63 \%$ of COVID19 patients required oxygen administration at presentation $(\mathrm{P}=0.02)$, with $9(38 \%)$ requiring a non-rebreather mask, 2 $(8 \%)$ continuous positive airway pressure (CPAP), and 3 $(13 \%)$ mechanical ventilation. Thus, the median $\mathrm{FiO} 2$ was $21 \%$ in controls, and $56 \%$ in COVID-19 patients $(\mathrm{P}<0.01$, Supplementary Table 1).

\section{Angiographic and Procedural Characteristics}

At angiography, no differences were observed between groups in terms of Thrombolysis in Myocardial Infarction (TIMI) flow rate at presentation, number of coronary vessels involved in critical stenosis, and culprit vessel (Table 4).

In 3 patients belonging to the COVID-19 group (12.5\%), no culprit lesion was identified at angiography. Thus, PCI was performed in 47 cases $(94 \%$ of total population, $85.5 \%$ and $100 \%$ of COVID and non-COVID patients, respectively, $\mathrm{P}=0.10$ ) with no difference between the groups.

No significant differences were recorded in relation to use of stents, Gp IIb/IIIa inhibitors, thrombus aspiration or mechanical support. COVID-19 patients showed a significantly higher rate of obstinate thrombosis at the culprit site $(47.6 \%$ vs. $11.5 \%, \mathrm{P}<0.01$; definition is provided in the Supplementary File), but final TIMI flow rates were similar, with a TIMI 2-3 flow in $90.5 \%$ and $100 \%$ of COVID-19 and non-COVID patients, respectively $(\mathrm{P}=0.19)$.

Staff at the catheterization laboratory adhered to specific protocols for protective equipment during donning and doffing. ${ }^{11}$ No cases of COVID-19 infection among the personnel were recorded during the study period.

\section{In-Hospital Outcome}

In-hospital death occurred in 42\% (10/24) of COVID-19 cases, compared to $4 \%(1 / 26)$ in non-COVID patients $(\mathrm{P}<0.01$, Table 5). The median time of death in the COVID19 group was $24.56 \mathrm{~h}$ [range:5.40-46.26h]. Seven out of the $10(70 \%)$ COVID-19 patients who died had been admitted to the hospital with severe acute respiratory failure $(\mathrm{P} / \mathrm{F}$ 


\begin{tabular}{|c|c|c|c|c|}
\hline & $\underset{(n=50)}{\text { All }}$ & $\begin{array}{l}\text { COVID } \\
(n=24)\end{array}$ & $\begin{array}{c}\text { Non-COVID } \\
(n=26)\end{array}$ & $P$ value \\
\hline All-cause death, $\mathrm{n}(\%)$ & $11(22.0)$ & $10(41.7)$ & $1(3.9)$ & $<0.01$ \\
\hline Acute hypoxic respiratory failure, $\mathrm{n}(\%)$ & & $4(16.7)$ & 0 & - \\
\hline Combined cardiorespiratory failure, $\mathrm{n}(\%)$ & & $4(16.7)$ & 0 & - \\
\hline Cardiogenic shock, $\mathrm{n}(\%)$ & & $1(4.2)$ & $1(3.9)$ & - \\
\hline Disseminated intravascular coagulation, $\mathrm{n}(\%)$ & & $1(4.2)$ & 0 & - \\
\hline Stroke, n (\%) & $3(6.0)$ & $3(12.5)$ & 0 & 0.10 \\
\hline Acute myocardial infarction (target lesion failure) & $1(2.0)$ & $1(4.2)$ & $0(0)$ & 0.47 \\
\hline Pulmonary embolism, $\mathrm{n}(\%)$ & $1(2.0)$ & $1(4.2)$ & $0(0)$ & 0.48 \\
\hline Bleeding, $n(\%)$ & $7(15.2)$ & $4(20.0)$ & $3(11.5)$ & 0.68 \\
\hline Minor bleeding, $\mathrm{n}(\%)$ & $6(11.8)$ & $3(12.5)$ & $3(11.5)$ & - \\
\hline Major bleeding, $n(\%)$ & $1(2.0)$ & $1(7.5)$ & 0 & - \\
\hline Acute kidney injury, $\mathrm{n}(\%)$ & $8(17.4)$ & $5(25.0)$ & $3(11.5)$ & 0.27 \\
\hline
\end{tabular}

COVID, Coronavirus Disease-2019. Data are presented as n (\%).

$<100$ ), whereas 6 patients had severe myocardial dysfunction (ejection fraction $\leq 35 \%$; Supplementary Table 2). Hypoxemic respiratory failure was the leading cause of death, contributing to $8 / 10(80 \%)$ of case fatalities, alone $(40 \%)$ or in combination with severe heart failure $(40 \%)$. The only recorded death in the non-COVID group occurred due to refractory cardiogenic shock, 26 days after procedure.

\section{Discussion}

Our results demonstrate a significant increase in mortality for STEMI patients with COVID-19 undergoing primary PCI, compared to non-COVID subjects, independent of similar angiographic results. STEMI patients with COVID19 often presented with severe respiratory failure and concurrent myocardial dysfunction, which were also the most frequent causes of death. In these patients, urgent percutaneous revascularization did not result in a similar survival benefit as observed in non-COVID patients, an important factor in selecting cases who might benefit from invasive procedures.

\section{Mortality in COVID-19 Patients Presenting With STEMI}

In general COVID-19 hospitalized populations, the reported timing of death occurred at a median of 2 weeks after symptom onset. ${ }^{13}$ Although the severity of respiratory involvement is highly variable, ${ }^{14}$ hypoxemic respiratory failure has been recognized as the leading cause of death, contributing to $\sim 60 \%$ of mortality, along with acute cardiac injury. ${ }^{15}$ A recent study on 3,988 patients from Italian intensive care units confirmed the impact of respiratory impairment, showing that a $10 \%$ increase in $\mathrm{FiO} 2$ upon admission was associated with a $24 \%$ increase in mortality. ${ }^{16}$ However, to date, no substantial data are available on the major determinants of death in the setting of STEMI patients.

In our COVID-19 STEMI patients, we found a highly significant difference in time and death rate compared to STEMI patients without COVID-19. Only 1 death was recorded in the non-COVID group $(3.8 \%)$, occurring 1 month after index event due to refractory cardiogenic shock. In contrast, in COVID-19 patients' mortality approached $50 \%(41.7 \%)$, at a median time of $25 \mathrm{~h}$. In this subgroup, we frequently observed severe respiratory insufficiency $(\mathrm{P} / \mathrm{F}<100)$, often associated with coexisting myocardial dysfunction, independently of the type and severity of CAD and treatment (conservative management vs. PCI). Indeed, no significant differences were detected among the groups (TIMI 2-3 flow was achieved in 90.5\% of COVID-19 groups and $100 \%$ of the non-COVID group, $\mathrm{P}=0.19$ ), and the final TIMI grade flow was not related to mortality.

\section{Coronary Artery Disease and Myocardial Dysfunction in STEMI Patients With Coexistent COVID-19}

Multiple studies have reported acute cardiac injury in the context of COVID-19 disease. ${ }^{13,17,18}$ Indeed, a temporal association of respiratory infections, and pneumonia in particular, with acute coronary syndromes has been demonstrated. ${ }^{2}$ Multiple mechanisms may trigger myocardial infarction, including imbalance between oxygen demand and supply, direct cardiomyocyte injury, microvascular dysfunction and coronary plaque instability. ${ }^{2,19}$

In our study, COVID-19 patients had a higher degree of myocardial dysfunction, possibly related to multifactorial mechanisms. No significant differences were identified in baseline characteristics of COVID-19 patients compared to non-COVID patients, although a tendency towards an older age and higher prevalence of diabetes was detected, in accordance with available literature. ${ }^{20}$ At angiography, no culprit lesions were detected in 3 COVID-19 patients. Two of them had diffuse hypokinesia with severely impaired ejection fraction and died due to cardiogenic shock within $48 \mathrm{~h}$, in keeping with the ominous early outcome reported for COVID-19 patients with STEMI, even in case of normal angiographic coronary arteries. ${ }^{21}$ Fulminant myocarditis mimicking STEMI has been suggested by multiple case reports as an underlying cause, ${ }^{17,22}$ possibly due to cardiac tropism of the virus, or a systemic hyper-inflammatory immune response. However, a different mechanism of diffuse patchy myocardial injury in COVID-19 presenting with STEMI and normal epicardial coronary vessels was documented in one case of this series, with autoptic detection of extensive microthrombi in capillaries and terminal arterioles, but no signs of myocarditis. ${ }^{23}$ Indeed, evidence on COVID-induced coagulopathy is increasing and microthrombi have been already documented also in the lungs and other organs. ${ }^{24,25}$ The higher 
rate of obstinate thrombosis we experienced during PCI may be another expression of such a hypercoagulable state.

\section{Treatment Strategies in Patients Presenting With STEMI and Coexisting COVID-19}

The role of fibrinolytic therapy over PCI in STEMI patients with confirmed or suspect COVID-19 has been addressed by multiple reports, but its use may vary considerably in different scenarios. ${ }^{26,27}$

In China, this treatment strategy was widely recommended for STEMI patients with symptom onset within $12 \mathrm{~h} .{ }^{28}$ Although there is no direct evidence of the outcomes of such a strategy compared to percutaneous revascularization, mortality rates in the Hubei province, where fibrinolysis was widely used, did not differ from other areas in the country. ${ }^{28}$ In our study, fibrinolysis was not used, considering the prevailing presentation of large infarcts with hemodynamic impairment. Although the lower exposure of health workers is in favor of fibrinolysis use, the absence of staff contamination observed in our study supports the feasibility of PCI, with proper observation of safety protocols. Nevertheless, the ominous outcomes of patients with severe respiratory failure may advocate for better treatment selection. Thus, management of STEMI patients with coexisting or suspected COVID-19 may need to better account for the challenges of respiratory impairment and cardiac injury.

\section{Study Limitations}

Our study has several limitations. First, it is a single center study, with a small sample size and a rather limited follow up. Second, it must be acknowledged that data were collected at the peak of a medical emergency, with hospital logistics stretched beyond the limit by the most intense wave of the pandemic. Thus, the completeness of data may be reasonably questioned, although the amount of missing information was minimal. Third, in our study, the vast majority of STEMI patients with coexistent COVID-19 presented with significant respiratory impairment, highlighted by the low median value of the $\mathrm{P} / \mathrm{F}$ ratio. The applicability of these results to subjects with mild COVID-19 involvement needs to be further assessed. Finally, additional geographical and temporal limitations may apply. Significant differences exist among countries in terms of ethnicity, epidemiology, and structural features of health systems. Moreover, viral outbreaks are dynamic events, and significant changes can alter their pattern over time across countries and even in the same area, accounting for significant variability between different reports. All these variables should be considered when interpreting our results and applying them to different settings.

\section{Conclusions}

Patients presenting with STEMI at the peak of the COVID-19 pandemic might have a relevant coexisting degree of respiratory impairment and myocardial damage, which can quickly offset the possible benefit of urgent coronary revascularization. Additional studies involving a larger number of patients hospitalized with STEMI and coexisting COVID-19, possibly derived from heterogeneous outbreak scenarios of different gravity, could be more useful in selecting good candidates for invasive coronary revascularization.

\section{Acknowledgments}

The authors would like to thank Maria Grazia Cattaneo and Fabio Martinelli for their support in data collection.

\section{Sources of Funding}

The investigators did not receive any form of financial support for the present study.

\section{Disclosures}

The authors have no conflicts of interest relevant to the current manuscript to disclose.

\section{Data Availability}

All de-identified individual data of participants will be shared. No additional documents will be shared. Data will be available upon publication and for at least 5 years. They will be shared upon legitimate request to the corresponding author. Data will be shared at a patientlevel and completely de-identified; they will be available for inclusion in meta-analyses and other additional investigations that may be deemed proper by the corresponding author.

\section{References}

1. Xiong TY, Redwood S, Prendergast B, Chen M. Coronaviruses and the cardiovascular system: Acute and long-term implications [published online ahead of print, 2020 Mar 18]. Eur Heart J 2020; 41: $1798-1800$.

2. Kwong JC, Schwartz KL, Campitelli MA, Chung H, Crowcroft NS, Karnauchow T, et al. Acute myocardial infarction after laboratory-confirmed influenza infection. $N$ Engl J Med 2018; 378: $345-353$.

3. Thygesen K, Alpert JS, Jaffe AS, Chaitman BR, Bax JJ, Morrow DA, et al; Executive Group on behalf of the Joint ESC/ACC/ AHA/WHF Task Force for the Universal Definition of Myocardial Infarction. Fourth universal definition of myocardial infarction (2018). J Am Coll Cardiol 2018; 72: 2231-2264.

4. Roffi M, Guagliumi G, Ibanez B. The obstacle course of reperfusion for STEMI in the COVID-19 pandemics. Circulation 2020; 141: $1951-1953$.

5. The European Society for Cardiology. ESC Guidance for the Diagnosis and Management of CV Disease during the COVID-19 Pandemic. https://www.escardio.org/Education/COVID-19-andCardiology/ESC-COVID-19-Guidance (accessed November 7, 2020).

6. Mahmud E, Dauerman HL, Welt FG, Messenger JC, Rao SV, Grines C, et al. Management of acute myocardial infarction during the COVID-19 pandemic. J Am Coll Cardiol 2020; 76: $1375-1384$.

7. Chieffo A, Stefanini GG, Price S, Barbato E, Tarantini G, Karam N, et al. EAPCI position statement on invasive management of acute coronary syndromes during the COVID-19 pandemic. Eur Heart J 2020; 41: 1839-1851.

8. Ferlini M, Andreassi A, Carugo S, Cuccia C, Bianchini B, Castiglioni B, et al. Centralization of the ST elevation myocardial infarction care network in the Lombardy region during the COVID-19 outbreak. Int J Cardiol 2020; 312: 24-26.

9. Corman VM, Landt O, Kaiser M, Molenkamp R, Meijer A, Chu DK, et al. Detection of 2019 novel coronavirus (2019-nCoV) by real-time RT-PCR. Euro Surveill 2020; 25: 2000045.

10. World Health Organization. Clinical management of severe acute respiratory infection (SARI) when COVID-19 disease is suspected. Interim guidance. https://www.who.int/docs/default-source/ coronaviruse/clinical-management-of-novel-cov.pdf (accessed November 7, 2020).

11. Tarantini G, Fraccaro C, Chieffo A, Marchese A, Tarantino FF, Rigattieri S, et al; GISE. Italian Society of Interventional Cardiology (GISE) position paper for Cath lab-specific preparedness recommendations for healthcare providers in case of suspected, probable or confirmed cases of COVID-19. Catheter Cardiovasc Interv 2020; 96: 839-843.

12. Fan E, Brodie D, Slutsky AS. Acute respiratory distress syndrome: Advances in diagnosis and treatment. JAMA 2018; 319: 698710 .

13. Bhatraju PK, Ghassemieh BJ, Nichols M, Kim R, Jerome KR, Nalla AK, et al. Covid-19 in critically ill patients in the Seattle region: Case series. N Engl J Med 2020; 382: 2012-2022. 
14. Wu Z, McGoogan JM. Characteristics of and important lessons from the Coronavirus Disease 2019 (COVID-19) Outbreak in China: Summary of a report of 72314 cases from the Chinese Center for Disease Control and Prevention. JAMA 2020; 323: $1239-1242$.

15. Ruan Q, Yang K, Wang W, Jiang L, Song J. Clinical predictors of mortality due to COVID-19 based on an analysis of data of 150 patients from Wuhan, China. Intensive Care Med 2020; 46: $846-848$.

16. Grasselli G, Greco M, Zanella A, Albano G, Antonelli M, Bellani G; COVID-19 Lombardy ICU Network. Risk factors associated with mortality among patients with COVID-19 in intensive care units in Lombardy, Italy. JAMA Intern Med 2020; 180: $1345-1355$.

17. Bangalore S, Sharma A, Slotwiner A, Yatskar L, Harari R, Shah $\mathrm{B}$, et al. ST-segment elevation in patients with Covid-19: A case series. N Engl J Med 2020; 382: 2478-2480.

18. Choudry FA, Hamshere SM, Rathod KS, Akhtar MM, Archbold RA, Guttmann OP, et al. High thrombus burden in patients with COVID-19 presenting with ST-segment elevation myocardial infarction. J Am Coll Cardiol 2020; 7610: 1168-1176.

19. Vejpongsa P, Kitkungvan D, Madjid M, Charitakis K, Anderson $\mathrm{HV}$, Arain S, et al. Outcomes of acute myocardial infarction in patients with influenza and other viral respiratory infections. $\mathrm{Am}$ J Med 2019; 132: 1173-1181

20. Shi S, Qin M, Shen B, Cai Y, Liu T, Yang F, et al. Association of cardiac injury with mortality in hospitalized patients with COVID-19 in Wuhan, China. JAMA Cardiol 2020; 5: 802 810.

21. Stefanini GG, Montorfano M, Trabattoni D, Andreini D, Ferrante G, Ancona M, et al. ST-elevation myocardial infarction in patients with COVID-19: Clinical and angiographic outcomes. Circulation 2020; 141: 2113-2116.
22. Tavazzi G, Pellegrini C, Maurelli M, Belliato M, Sciutti F, Bottazzi A, et al. Myocardial localization of coronavirus in COVID-19 cardiogenic shock. Eur J Heart Fail 2020; 22: 911 915.

23. Guagliumi G, Sonzogni A, Pescetelli I, Pellegrini D, Finn AV. Microthrombi and ST-segment-elevation myocardial infarction in COVID-19. Circulation 2020; 142: 804-809.

24. Ackermann M, Verleden SE, Kuehnel M, Haverich A, Welte T, Laenger F, et al. Pulmonary vascular endothelialitis, thrombosis, and angiogenesis in Covid-19. N Engl J Med 2020; 383: 120-128.

25. Levi M, Thachil J, Iba T, Levy JH. Coagulation abnormalities and thrombosis in patients with COVID-19. Lancet Haematol 2020; 6: e438-e440.

26. Welt FGP, Shah PB, Aronow HD, Bortnick AE, Henry TD, Sherwood MW, et al; American College of Cardiology's Interventional Council and the Society for Cardiovascular Angiography and Interventions. Catheterization laboratory considerations during the Coronavirus (COVID-19) pandemic: From the ACC's Interventional Council and SCAI. J Am Coll Cardiol 2020; 75: $2372-2375$.

27. Daniels MJ, Cohen MG, Bavry AA, Kumbhani DJ. Reperfusion of ST-segment-elevation myocardial infarction in the COVID-19 era: Business as usual? Circulation 2020; 141: $1948-1950$.

28. Xiang D, Xiang X, Zhang W, Yi S, Zhang J, Gu X, et al. Management and outcomes of patients with STEMI during the COVID-19 pandemic in China. J Am Coll Cardiol 2020; 76: $1318-1324$

\section{Supplementary Files}

Please find supplementary file(s); http://dx.doi.org/10.1253/circj.CJ-20-1166 